\title{
Adverse genetic effects induced by chemical or physical environmental pollution
}

\author{
Hagen Scherb • Kristina Voigt
}

Received: 1 March 2010 /Accepted: 23 March 2010/Published online: 14 April 2010

(C) Springer-Verlag 2010

Over the past decades, many animal experiments and epidemiological studies have revealed the vulnerability of living beings exposed to adverse chemical or physical environmental conditions.

The effect of environmental contaminants on health is a major concern because exposure is associated with a number of diseases, including cancer, diabetes, and infertility (Edwards and Myers 2007). Children in particular are subject to enhanced risks from pollution for several reasons (Nelson et al. 1996). Developing organs are extremely sensitive to toxic effects; a child absorbs more pollutants compared to its weight than an adult (Woodruff et al. 1997). Moreover, it has become increasingly clear that some cancers and birth defects stem from common exposures that occur early in life or even before conception. Paternal and maternal exposure can induce germ cell cancers in infants. For example, paternal exposure before conception may increase the risk of birth defects in the offspring. Male infants are at higher risk than female infants for a number of congenital abnormalities. Thus, the role of exposure extends to the period of spermatogenesis (Garry et al. 1996). This highlights the necessity of investigations that combine developmental defects and childhood cancer as indicators of cell differentiation that reflect potential peri-conceptional, prenatal, and early childhood exposures (Moller and Skakkebaek 1996; Damgaard et al. 2006).

Environmental ionizing radiation is of special interest as it can induce germ cell mutations and somatic mutations

\footnotetext{
H. Scherb $(\bowtie) \cdot K$. Voigt

Institute of Biomathematics and Biometry, Helmholtz Zentrum München-German Research Center for Environmental Health, Ingolstaedter Landstr. 1, 85764 Neuherberg, Germany

e-mail: scherb@helmholtz-muenchen.de
}

alike. Children's development is known to be especially radiosensitive, from conception through the embryonic and fetal periods, to infancy. Recently, it has been shown that childhood cancers are significantly increased in the vicinity of German nuclear reactors (Spix et al. 2008; Nussbaum 2009). In this context, the Chernobyl accident is of great interest and importance. Thyroid cancer in children occurred very early and in far too great a number of cases relative to previous (pretended) experience (Balter 1996). In fact, the World Health Organization and the International Atomic Energy Agency have failed to objectively investigate and communicate the many detrimental health effects attributable to the Chernobyl catastrophe (Tickell 2009; Yablokov et al. 2010). A possible genetic effect of ionizing radiation - an impact on the human sex ratio at birth (Schull and Neel 1958) - has not been investigated at all by the national or international institutions nor by the scientific community despite the simplicity and exactness of this measure, not to speak of the important implications if this trait was significantly distorted after Chernobyl. The failure of the scientific community worldwide to look at the sex odds after Chernobyl is a staircase wit of history. We investigated trends in the sex odds before and after the Chernobyl accident (1982-1992) in several European countries and found a significant jump in the sex odds trends after Chernobyl (Scherb and Voigt 2007). In this Issue of "Environmental Science and Pollution Research," we show a distorted sex odds in all of Europe analyzing trends from 1975 to 2007 . We also disclose similar effects in Europe and in the USA after the atmospheric atomic bomb testing from 1945 to 1963 (Scherb and Voigt 2010). Our findings allow the estimation of the likely order of magnitude of one million missing children across Europe and parts of Asia after Chernobyl till to date. Because a recovery of the disturbed sex ratio is not foreseeable, the 
number of missing children will still be increasing in many years to come.

The support of environmental research by statistical and mathematical data analysis methods in order to demonstrate effects of adverse environmental conditions as well as to assess possible remediation measures is essential.

\section{References}

Balter M (1996) Children become the first victims of fallout. Science 272(5260):357-360

Damgaard IN, Skakkebaek NE, Toppari J, Virtanen HE, Shen H, Schramm KW, Petersen JH, Jensen TK, Main KM (2006) Persistent pesticides in human breast milk and cryptorchidism. Environ Health Perspect 114(7):1133-1138

Edwards TM, Myers JP (2007) Environmental exposures and gene regulation in disease etiology. Environ Health Perspect 115 (9): $1264-1270$

Garry VF, Schreinemachers D, Harkins ME, Griffith J (1996) Pesticide appliers, biocides, and birth defects in rural Minnesota. Environ Health Perspect 104(4):394-399

Moller H, Skakkebaek NE (1996) Risks of testicular cancer and cryptorchidism in relation to socio-economic status and related factors: case-control studies in Denmark. Int J Cancer 66(3):287-293

Nelson RP Jr, DiNicolo R, Fernandez-Caldas E, Seleznick MJ, Lockey RF, Good RA (1996) Allergen-specific IgE levels and mite allergen exposure in children with acute asthma first seen in an emergency department and in nonasthmatic control subjects. J Allergy Clin Immunol 98(2):258-263

Nussbaum RH (2009) Childhood leukemia and cancers near German nuclear reactors: significance, context, and ramifications of recent studies. Int J Occup Environ Health 15(3):318-323

Scherb H, Voigt K (2007) Trends in the human sex odds at birth in Europe and the Chernobyl Nuclear Power Plant accident. Reprod Toxicol 23(4):593-599

Scherb H, Voigt K (2010) The human sex odds at birth after the atmospheric atomic bomb tests and after Chernobyl. Environ Sci Pollut Res (in press)

Schull WJ, Neel JV (1958) Radiation and the sex ratio in man. Science 128(3320):343-348

Spix C, Schmiedel S, Kaatsch P, Schulze-Rath R, Blettner M (2008) Case-control study on childhood cancer in the vicinity of nuclear power plants in Germany 1980-2003. Eur J Cancer 44(2):275284

Tickell O (2009) Toxic link: the WHO and the IAEA: A 50-year-old agreement with the IAEA has effectively gagged the WHO from telling the truth about the health risks of radiation. The Guardian, Thursday 28 May 2009. http://www.guardian.co.uk/commentisfree/ 2009/may/28/who-nuclear-power-chernobyl

Woodruff TJ, Grillo J, Schoendorf KC (1997) The relationship between selected causes of postneonatal infant mortality and particulate air pollution in the United States. Environ Health Perspect 105(6):608-612

Yablokov AV, Nesterenko VB, Nesterenko AV (2010) Chernobyl: consequences of the catastrophe for people and the environment. Wiley, Berlin 